\title{
EDITORIAL
}

\section{COPD: functional status, health status and primary care}

See linked articles by Tsiligianni et al. on pg 257 and Kocks et al. on pg 269

\section{*Paul W Jones ${ }^{\mathrm{a}}$ \\ a Professor of Respiratory Medicine Head of the Division of Clinical Science St George's, University of London, UK}

\section{*Correspondence:}

Professor Paul W Jones

Professor of Respiratory Medicine Head of the Division of Clinical Science St George's, University of London Cranmer Terrace

London

SW17 ORE

UK

Tel: +44208725 5371

E-mail: pjones @sgul.ac.uk

Commissioned article Not externally peer-reviewed Accepted 27th July 2011 Online 2nd August 2011
This issue of the PCRJ contains two very useful papers about the impact of COPD on patients. One is a systematic review of health-related quality of life ${ }^{1}$ and the other focuses on patients' functional status. ${ }^{2}$

The term 'health-related quality of life' has a catchy acronym (HRQoL) and is used widely and often interchangeably with 'health status'. 'These are indeed related concepts and are derived from the same source - the patient's report of the effect of the disease on their daily life and well-being. However, it is still worth differentiating between them. Impaired HRQoL is a clinical outcome experienced by the patient. ${ }^{3}$ The factors that influence an individual's quality of life (QoL) are as varied as humankind; the inability to walk a dog when the weather is bad may have a very large effect on one patient's QoL but not on another's. It is difficult to measure most clinical outcomes as experienced by patients (death being the exception), so markers of outcome are used. ${ }^{3}$ These are standardised measurements that assess each person as if they were a 'typical' patient - rather far away from the concept of individual HRQoL. For this reason, the term HRQoL should be reserved for use when discussing the useful but abstract construct of (HR)QoL in individuals, whereas health status (sadly without a nice acronym) should be used when the context is standardised measurement of the impact of disease.

Validation of health status instruments is a complex task, and the review by Tsiligianni et al. documents exhaustively many published correlations between health status questionnaires and other important markers of disease severity. ' Yet this does not prove that the questionnaires are valid; it just shows that they have the associations that might be expected of something designed to measure impaired health. Recently, however, the development of the COPD Assessment Test (CAT), a new COPD questionnaire for use in routine practice, ${ }^{4}$ provides a powerful piece of evidence for the existence of the underlying construct 'HRQOL in COPD'. The CAT was developed using modern questionnaire methodology and has only eight items and a relatively unusual but simple scoring system. This concise instrument has been compared with the SGRQ - an older questionnaire also designed as a marker of HRQoL in COPD but with 40-50 items identified using an entirely different methodology and with a very different structure and scoring process. The correlation between these two instruments is very good, suggesting that the underlying construct that both are trying to measure (HRQoL in COPD) is valid and reliable. ${ }^{4}$

Impaired function is a narrower construct than health status and as a clinical outcome it is conceptually very useful. However, there is much less agreement about the operational definition of functional impairment. In their comprehensive review, Kocks et al. have compared many different functional instruments, pointing out that the terms functional status, functional capacity, exercise capacity and exercise tolerance are often used interchangeably. ${ }^{2}$ The methods of measurement also vary widely - from physical measurements of distance walked, to oxygen consumption on an ergometer, to questionnaires. Even within a single domain of measurement - for example, patient subjective report - there is considerable variability in content and depth across the various generic and disease-specific instruments that have been developed. ${ }^{5}$ It is therefore difficult to read the review by Kocks et al. and come away with any conclusion other than the need for some order to be brought to the field. Perhaps the PROactive programme (www.proactivecopd.com) will achieve this. At the same time it is important to note that a wide range of instruments has been developed and validated $-\mathrm{a}$ testimony to the recognised importance of measuring impaired function in COPD. The 
comparison methodologies employed by Kocks et al. were relatively simple and somewhat subjective, ${ }^{2}$ but the authors do identify two valid and reliable instruments that may be particularly useful in a primary care setting - the MRC Dyspnoea questionnaire and the CCQ (although the latter is in many ways more preferable despite being longer since it is far more comprehensive than the MRC). The CAT does not feature in their review because it was under development at the time.

The term 'surrogate marker' is commonly used but often tautologically, since a marker is a surrogate measurement of a clinical outcome. Surrogate markers do exist, however, as substitutes for other more relevant markers. Until the last few years, the $\mathrm{FEV}_{1}$ has been the ubiquitous surrogate marker for functional status, health status and much else in COPD. As is pointed out in both these papers, ${ }^{1,2}$ there is only a weak correlation between $\mathrm{FEV}_{1}$ and markers of impaired HRQoL and functional status. Remarkably, there have been few studies that have reported the relationship between change in $\mathrm{FEV}_{1}$ and change in health status with treatment. At a population or study level there is a reasonable correlation, ${ }^{6}$ but at an individual patient level the correlation is very weak. ${ }^{7}$ For this reason we should measure the marker of interest and not use a poor surrogate. Even patient-reported history of exacerbations is a more reliable predictor of future exacerbations than GOLD stage. ${ }^{8}$

Therefore, good patient-reported outcome instruments are now available for routine use in the management of COPD patients in primary care. But to what end? Questionnaire properties can be divided into three main categories: discriminative - the ability to detect differences between patients with different degrees of severity; evaluative - the ability to detect changes and/or response to treatment; and prognostic - the ability to predict future health events. The CCQ, MRC and CAT have good discriminative properties that complement the $\mathrm{FEV}_{1}$ and provide useful information to guide management decisions - for example, initiating treatment and referral for pulmonary rehabilitation or specialist opinion. As evaluative instruments, unfortunately none have sufficient signal/noise ratio to provide a reliable assessment of whether an individual patient has responded to a specific treatment (and the $\mathrm{FEV}_{1}$ is no better). However, the CCQ and CAT would be good audit tools. One potentially very important application, yet to be explored fully, is in monitoring individual patients to identify those who are deteriorating, and those who have failed to show a clear and sustained response to treatment or have not recovered fully from an exacerbation. Finally, very little is known about their use as prognostic markers, although studies are underway.

What conclusions can be drawn from these two papers? ${ }^{1,2}$ The first is the recognition that the $\mathrm{FEV}_{1}$, whilst being fundamental for the diagnosis of COPD, tells us little about a patient's ability to function at home and in society, and very little about their HRQoL. The second is that there are valid and reliable instruments that are easy to use in clinical practice. Routine use of these measures - that are as quick to use and score as a peak flow, and even faster than spirometry - tells us a lot about the impact of the disease and the health of the patient. Some doctors will never measure anything, but for those who would like to know more about the overall impact of COPD on their patient, it is now possible to get more useful information more quickly than having the patient blow a forced expiratory manoeuvre.

\section{Conflicts of interest}

PWJ developed the SGRQ and CAT questionnaires.

\section{References}

1. Tsiligianni I, Kocks J, Tzanakis N, Siafakas N, van der Molen T. Factors that influence disease-specific quality of life or health status in patients with COPD: a systematic review and meta-analysis of Pearson correlations. Prim Care Respir J 2011;20:257-68. http://dx.doi.org/10.4104/pcrj.2011.00029

2. Kocks J, Asijee GM, Tsiligianni IG, Kerstjens HAM, van der Molen T. Functional status measurement in COPD: a review of available methods and their feasibility in primary care. Prim Care Respir J 2011;20:269-75. http://dx.doi.org/10.4104/ pcrj.2011.00031

3. Jones PW, Agusti AGN. Outcomes and markers in the assessment of chronic obstructive pulmonary disease. Eur Respir J 2006;27:822-32. http://dx.doi.org/10.1183/09031936.06.00145104

4. Jones PW, Harding G, Berry P, Wiklund I, Chen WH, Kline Leidy N. Development and first validation of the COPD Assessment Test. Eur Respir J 2009;34:648-54. http://dx.doi.org/10.1183/09031936.00102509

5. Stull DE, Leidy NK, Jones PW, Stahl E. Measuring functional performance in patients with COPD: a discussion of patient-reported outcome measures. Curr Med Res Opin 2007;23:2655-65. http://dx.doi.org/10.1185/030079907X233133

6. Westwood M, Bourbeau J, Jones PW, Cerulli A, Capkun-Niggli G, Worthy G. Relationship between FEV1 change and patient-reported outcomes in randomised trials of inhaled bronchodilators for stable COPD: a systematic review. Resp Res 2011;12:40. http://dx.doi.org/10.1186/1465-9921-12-40

7. Jones PW. Health status measurement in chronic obstructive pulmonary disease. Thorax 2001;56:880-7. http://dx.doi.org/10.1136/thorax.56.11.880

8. Hurst JR, Vestbo J, Anzueto A, et al. Susceptibility to Exacerbation in Chronic Obstructive Pulmonary Disease. N Engl J Med 2010;363:1128-38. http://dx.doi.org/10.1056/NEJMoa0909883

Available online at http://www.thepcrj.org 